\title{
ANALISIS STRUKTUR PADA GIRDER OVERHEAD CRANE SWL 30 TON
}

\author{
Jefriansyah'), Ma'ruf ${ }^{2)}$ \\ 1), 2) Program Studi Teknik Mesin, Fakultas Teknik, Universitas Lambung Mangkurat \\ JL. Akhmad Yani Km. 36 Banjarbaru, Kalimantan selatan, 70714 \\ Email:jefriansyah.hiqua@gmail.com
}

\begin{abstract}
Overhead crane is a device used to move goods. Overhead cranes are very important during the production period, if there is a problem in the overhead crane, it can disrupt the production process. Therefore, load testing was conducted to determine the results of the girder deflection, whether large deflection is still within the limits that are allowed or not. This study to calculate the girder overhead crane occur in the loading variations, and adjust the properties of the material used. The amount of deflection is calculated using the equation Castigliano theory. research on the loading of 28.7 tons, 30 tons, and 37.5 tons with theoretical calculations obtained deflection value calculation results is $6,060 \mathrm{~mm}, 6,335 \mathrm{~mm}$, and 7.918 for the imposition of the middle girder (1/2span). 5,191mm, 5,410mm and 6,763mm for the loading side (1 / 3span). The simulation results are 5,649mm, 5,834mm, and 6.898 for the imposition of the middle girder (1 / 2span) and 4,986mm, 5,101mm and 6,032mm for the loading side (1 / 3 span). The results obtained have great value below allowable deflection value is $23.75 \mathrm{~mm}$.
\end{abstract}

Keywords: Girder Overhead crane, load variation, deflection.

\section{PENDAhUluan}

Overhead crane merupakan salah satu fasilitas sebagai sarana pemindahan barang yang sangat penting untuk berbagai kegiatan produksi. Mengingat besarnya fungsi dan nilai resiko, maka selama periode produksi, crane harus diperiksa dan dirawat dengan baik. Dengan adanya pemeriksaan maka temuan-temuan dini terhadap kerusakan atau kemunduran kekuatan sebuah overhead crane dapat ditemukan, dan akhirnya untuk dapat direkomendasi atau diganti. Overhead crane dapat dikatakan layak kerja setelah dilakukannya pengujian beban, pengujian lapangan dan pemeriksaan visual. Pengujian beban dilakukan untuk mengetahui hasil defleksi pada girder, apakah besar defleksi tersebut masih dalam batas yang di ijinkan atau tidak.

Pengujian beban dilakukan untuk mengetahui hasil defleksi pada girder, apakah besar defleksi tersebut masih dalam batas yang di ijinkan atau tidak. Pengujian uji beban statis dilakukan dengan besar beban $0 \mathrm{~s} / \mathrm{d}$ SWL maximum, sedangkan pengujian beban dinamis dilakukan pada beban $100 \%$ - 125\% X SWL maksimum. Teknik yang di terapkan Pada penelitian ini menggunakan perhitungan teoritis dangan metode castigliano dan simulasi menggunakan autodesk inventor 2014, bagaimana hasil perhitungan pada girder overhead crnare sebagai bagian dari analisa struktur dengan variasi pembebanan, dan menyesuaikan dengan sifat material yang digunakan. 


\section{KAJIAN PUSTAKA}

Overhead crane adalah pesawat atau alat yang digunakan untuk memindahkan, mengangkat muatan baik bahan atau barang atau orang secara vertikal dan atau horizontal dalam jarak yang ditentukan atau dapat juga didefinisikan sebagai suat alat yang dikonstruksi atau dibuat secara khusus untuk mengangkat naik dan menurunkan barang. Salah satu komponen overhead crane yaitu girder, girder adalah satu konstruksi dimana trolly menggantung dan bergerak.

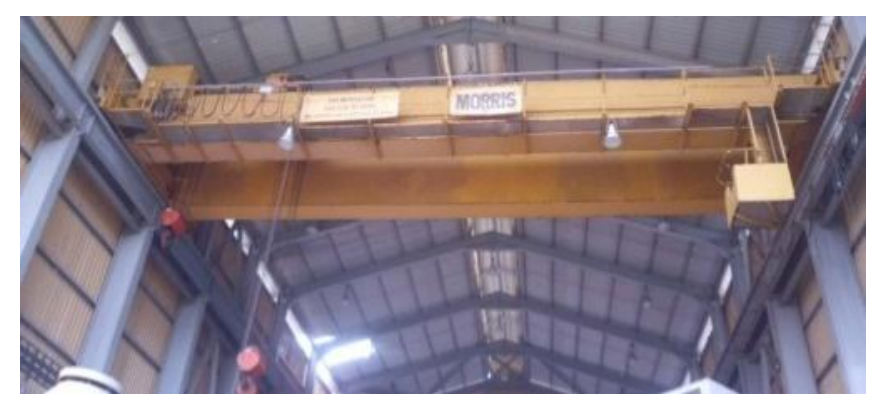

Gambar 1. Overhead Crane

Pengujian beban merupakan pengujian yang sangat penting dalam pengujian crane. Sebab, pada testing ini crane akan diuji keseluruhan fungsi alat dan unjuk kerja pengangkatan pada semua kondisi operasi dengan beban yang mendekati, sama atau bahkan melebihi kapasitas maksimumnya. Pengujian beban pada overhead crane SWL 30 Ton dilakukan dengan beban tidak lebih dari $100 \%$ rated load dan diuji kesemua arah serta fungsi. Pengujian over load dilakukan dengan beban tidak lebih dari 125\% dari rated load. Menurut C.alkin (2005) perhitungan desain konvensional yang diusulkan dan standar DIN dilakukan untuk memverifikasi tingkat stres dan defleksi, sebagai hasil untuk desain overhead crane dapat diusulkan.

Defleksi merupakan perubahan bentuk pada balok dalam arah y akibat adanya pembebanan vertikal yang diberikan pada balok atau batang. Defleksi diukur dari permukaan netral awal ke posisi netral setelah terjadi deformasi. Konfigurasi yang diasumsikan dengan deformasi permukaan netral dikenal sebagai kurva elastis dari balok. Gambar 2 (a) memperlihatkan balok pada posisi awal sebelum terjadi deformasi dan gambar 2 (b) adalah balok dalam konfigurasi terdeformasi yang diasumsikan akibat pembebanan. 


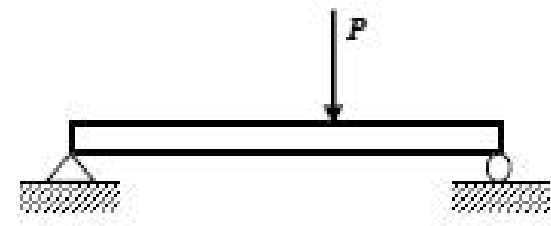

(a)

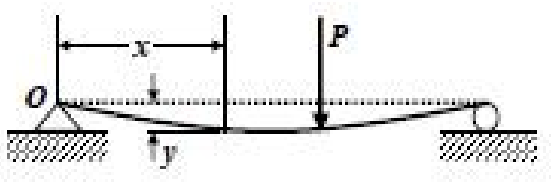

(b)

Gambar 2. Defleksi pada balok

Jarak perpindahan $\mathrm{Y}$ didefinisikan sebagai defleksi balok. Hal hal yang mempengaruhi defleksi yaitu : Kekakuan batang ,Semakin kaku suatu batang maka lendutan batang yang akan terjadi pada batang akan semakin kecil. Besar kecilnya gaya yang diberikan, Besar kecil gaya yang diberikan pada batang berbanding lurus dengan besarnya defleksi yang terjadi, dengan kata lain semakin besar beban yang dialami batang maka defleksi yang terjadipun semakin besar. Jenis tumpuan yang diberikan, Jumlah reaksi dan arah pada tiap jenis tumpuan berbeda-beda, jika karena itu besarnya defleksi pada penggunaan yang berbeda-beda tidaklah sama, semakin banyak reaksi dari tumpuan yang melawan gaya dari beban maka defleksi yang terjadi pada tumpuan rol lebih besar dari tumpuan pin (pasak) dan defleksi yang terjadi pada tumpuan pin lebih besar dari tumpuan jepit. Jenis beban yang terjadi pada batang, beban terdistribusi merata dengan beban titik, keduanya memiliki kurva defleksi yang berbeda-beda. Pada beban terdistribusi merata slope yang terjadi pada bagian batang yang paling dekat lebih besar dari slope titik, ini karena sepanjang batang mengalami beban sedangkan pada beban titik hanya terjadi pada beban titik tertentu saja.

Pada kasus girder overhead crane (misalnya) yang ditumpu kedua ujungnya (posisi horizontal), jika diberikan beban pada girder maka girder tersebut akan mengalami defleksi. Besar defleksi yang terjadi dapat ditentukan dengan menggunakan metode metode yang ada.

Teorema Castigliano dapat digunakan untuk mencari defleksi.

$$
\Delta_{1}=\frac{d W}{d P}
$$

Metode ini sering disebut sebagai metode penurunan parsiil (Partial Deriative). Usahausaha luar W yang bekerja pada balok adalah sama dengan usaha dalam yang tersimpan dalam balok $\frac{1}{2} \sum S d l_{\text {atau : }}$

$$
W=\frac{1}{2} \sum S d l
$$

$\underset{\text { Subtitusikan }}{ } S=\frac{M y}{I} d A$ dan $d L=\frac{M y}{I} \frac{1}{E} d x \quad$ ke dalam persamaan diatas, sehingga: 


$$
\begin{aligned}
& W=\frac{1}{2} \Sigma\left(\frac{M y}{I} d A\right)\left(\frac{M y}{I} \frac{1}{E} d x\right) \\
& W=\frac{1}{2} \int_{0}^{L} \int_{0}^{A} y^{2} d A \frac{M^{2}}{E I^{2}} d x \\
& W=\frac{1}{2} \int_{0}^{L} \frac{M^{2}}{E I} d x
\end{aligned}
$$

Subtitusikan persamaan (2.3) ke dalam persamaan (2.1), diperoleh :

$$
\Delta_{1}=\frac{d W}{d P}=\frac{d \frac{1}{2} \int_{0}^{L} \frac{M^{2}}{E I} d x}{d P}=\int_{0}^{L} \frac{M \frac{d M}{d P}}{E I} d x
$$

Persamaan defleksi:

$$
\Delta_{1}=\int_{0}{ }_{0} \frac{M \frac{d M}{d P}}{E I} d x
$$

Dimana :

$$
\begin{aligned}
& M \text { adalah Momen }(\mathrm{Nm}) \\
& E \text { adalah Modulus Elastis }\left(\mathrm{N} / \mathrm{mm}^{2}\right) \\
& I \text { adalah momen Inersia }\left(\mathrm{mm}^{4}\right)
\end{aligned}
$$

Program autodesk inventor 2014, Program komputer ini dapat digunakan untuk menganalisa masalah struktur khususnya defleksi pada girder overhead crane. Urutan Kerjanya adalah sebagai berikut:

1. Membuat sebuah model/part yang akan dianalisa.

2. Memilih material untuk model/part

3. Mengatur kekerasan/kehalusan mesh

4. Membei beban (load), beban dapat berupa: 

i) gaya (Force)
ii) moment
iii) bearing load pada permukaan silindris.
iv) bearng load pada permukaan silindris.
v) beban karna gravitasi (Body Load)

5. memberi tumpuan (constraint), dapat berupa:

i) fixed constraint

ii) pin constrain

iii) frictionless constraint

6. menjalankan analisa tegangan

7. menvisualisasikan hasil dan simulasi

8. membuat laporan dalam bentuk file doc

\section{METODE PENELITIAN}

Pada penulisan penelitian ini metode pengumpulan data yang digunakan adalah dengan menggunakan penelusuran literatur, wawancara dan dokumentasi. Metode literatur menggunakan cara mengumpulkan data tertulis yang berkaitan dengan masalah penulisan dan juga jurnal dari penelitian sebelumnya dalam hal analisa stuktur pada girder overhead crane. Interview dengan cara melakukan tanya jawab dengan Engineer di lapangan maupun pembimbing lapangan untuk memperoleh informasi yang berhubungan analisa struktur. Dokumentasi dilakukan untuk mengumpulkan gambar girder overhead crane.

Setelah melakukan pengumpulan data, dilakukan perhitungan defleksi dengan menggunakan teori castigliano dan simulasi menggunakan autodesk inventor 2014, kemudian membandingkan hasil perhitungan teoritis dan simulasi dengan nilai defleksi yang di ijinkan yaitu $23,75 \mathrm{~cm}$. Variabel dalam penelitian terdiri dari variabel bebas dan variabel terikat. Variabel bebas adalah Pengaruh pembebanan 28,7 ton, 30 ton dan 37,5 ton pada girder overhead crane. Variabel terikat adalah besar nilai defleksi pada girder overhead crane.

\section{HASIL PEMBAHASAN}

Overhead crane mengalami pembebanan pada bagian tengah girder, nilai pembebanan yang diberikan adalah adalah sebesar 281260 N, 294000 N, dan 367500 N. Pada gambar 3 merupakan gambar komponen Girder Overhead Crane yang akan dianalisa dengan menggunakan software Autodesk Inventor 2014, analisa yang akan dilakukan adalah berupa uji pembebanan pada Girder. 


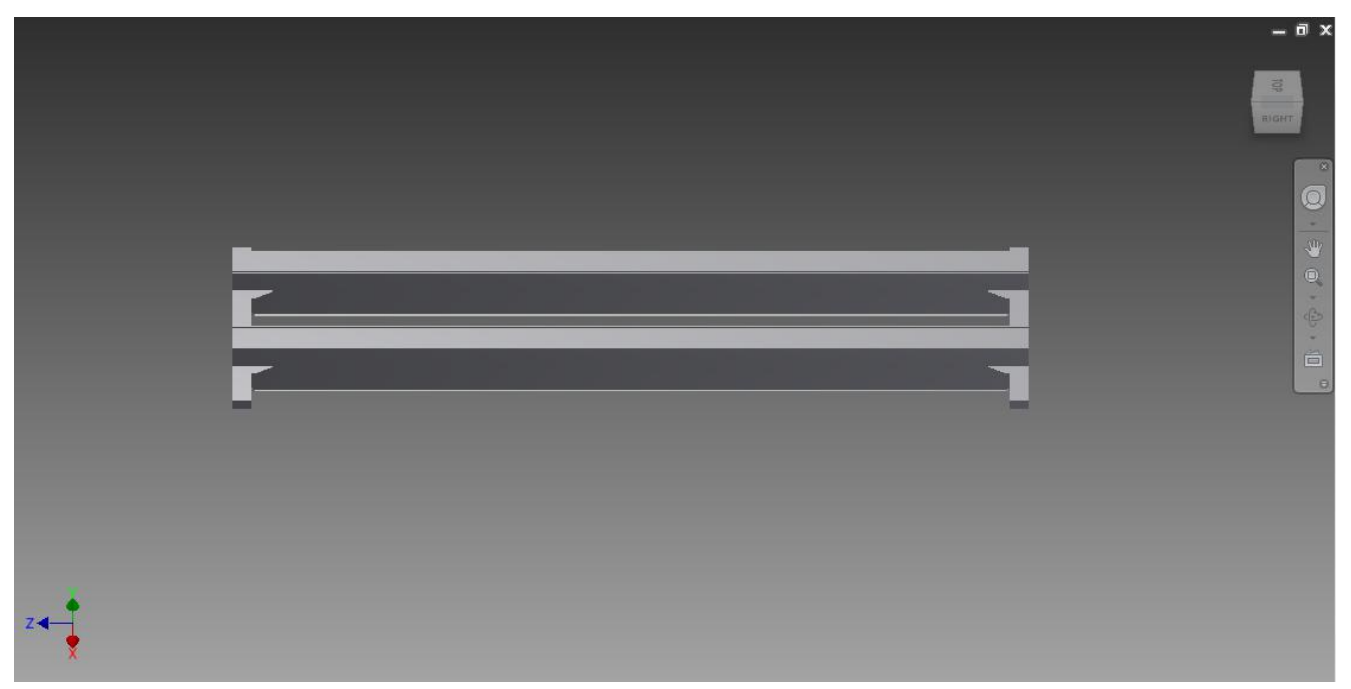

Gambar 3. komponen Girder Overhead Crane

Tabel 1 Hasil Perhitungan Defleksi

\begin{tabular}{|c|c|c|c|c|}
\hline No & Letak pembebanan & $\begin{array}{l}\text { Beban } \\
\text { (Ton) }\end{array}$ & $\begin{array}{l}\text { Defleksi yang di } \\
\text { ijinkan } \\
(\mathrm{mm})\end{array}$ & $\begin{array}{c}\text { Defleksi (Teori } \\
\text { castigliano) } \\
(\mathbf{m m})\end{array}$ \\
\hline 1 & \multirow{3}{*}{$\begin{array}{l}\text { Bagian tengan girder } \\
\qquad(1 / 2 \text { span })\end{array}$} & 28,7 & \multirow{6}{*}{23,75} & 6,060 \\
\hline 2 & & 30 & & 6,335 \\
\hline 3 & & 37,5 & & 7,918 \\
\hline 4 & \multirow{3}{*}{$\begin{array}{l}\text { Bagian samping girder } \\
\qquad(1 / 3 \text { span })\end{array}$} & 28,7 & & 5,191 \\
\hline 5 & & 30 & & 5,410 \\
\hline 6 & & 37,5 & & 6,763 \\
\hline
\end{tabular}

Tabel 2 Hasil Simulasi Defleksi 


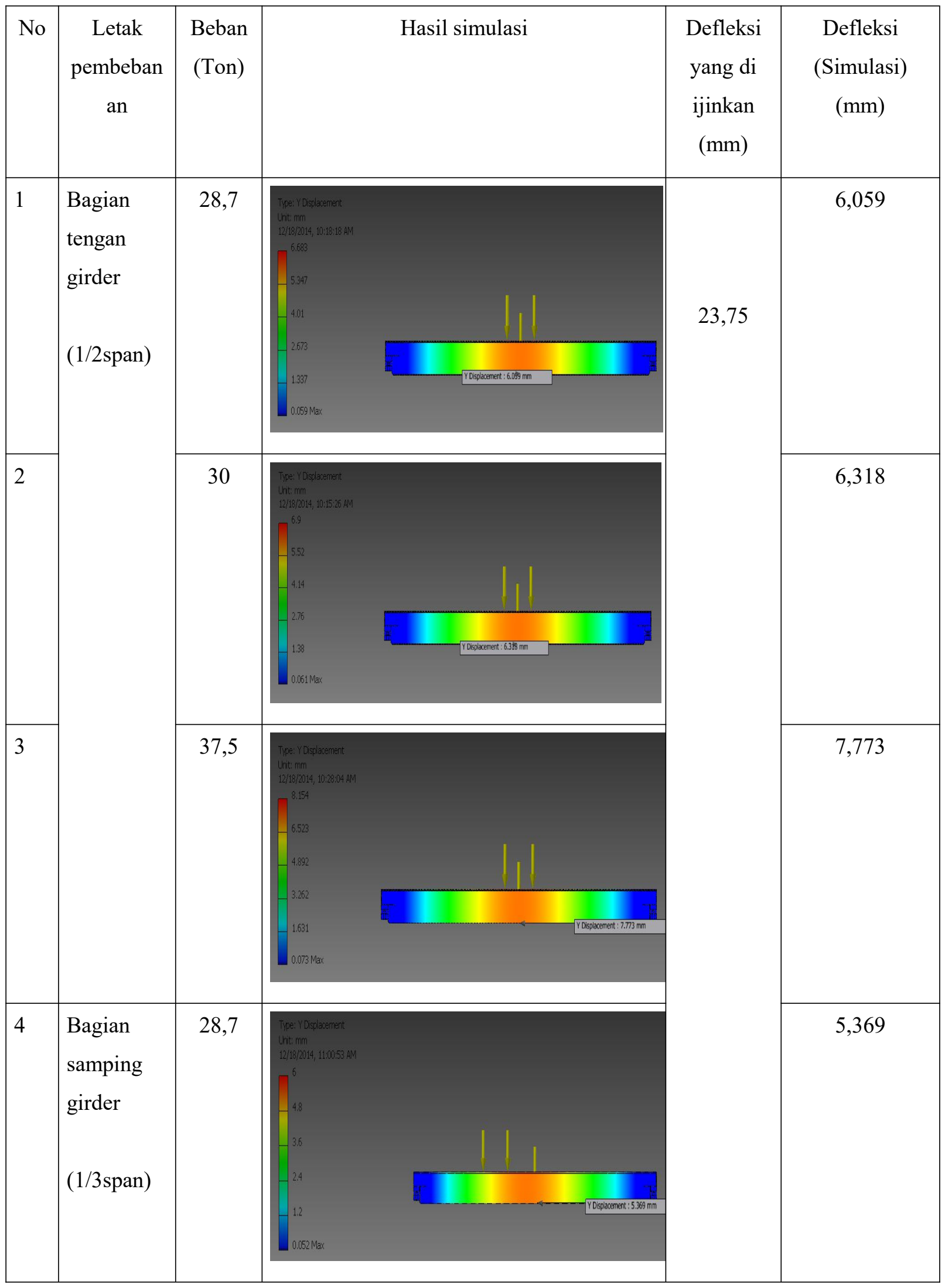



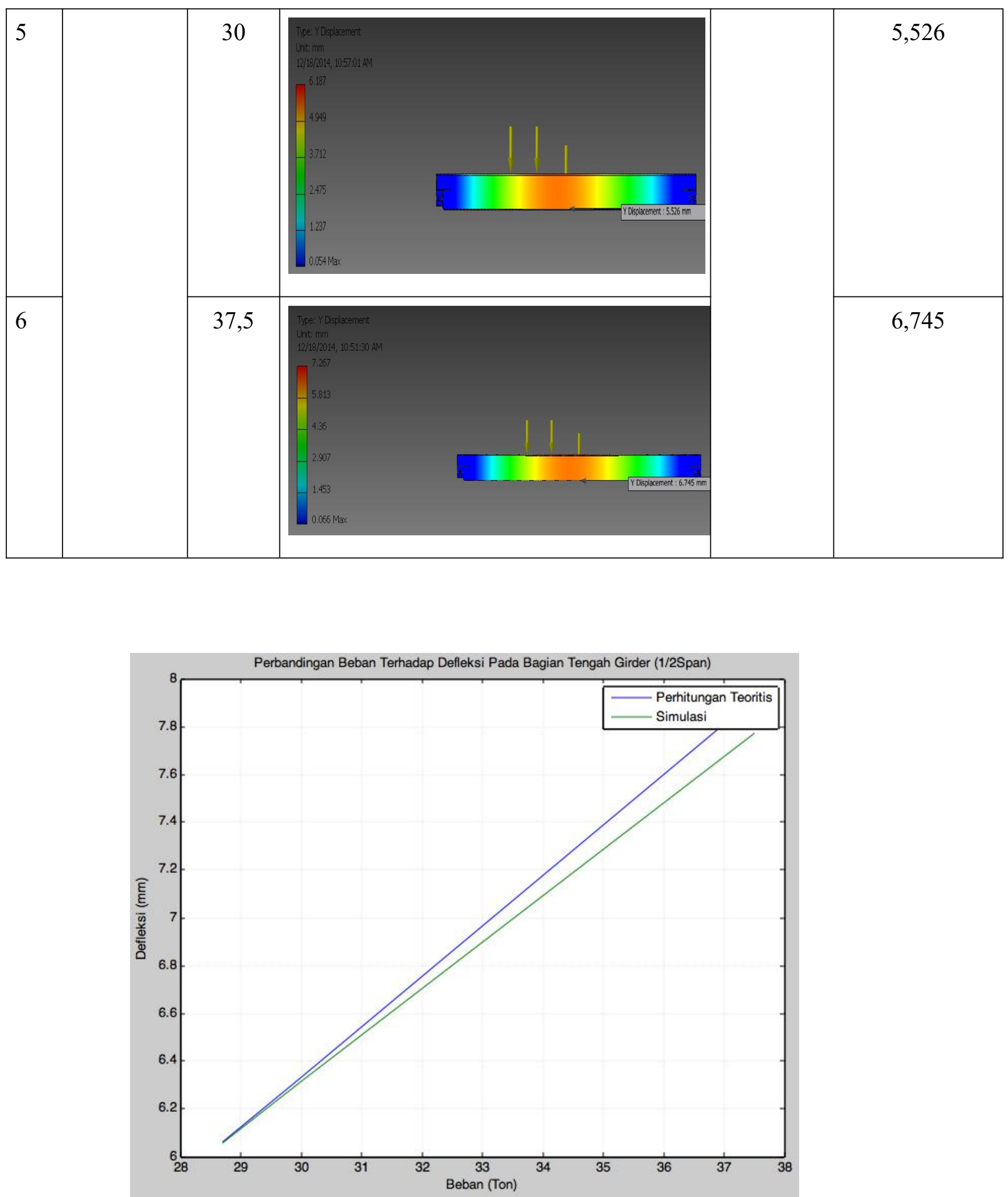

Gambar 4. Grafik perbandingan defleksi terhadap pembebanan pada bagian tengah girder 


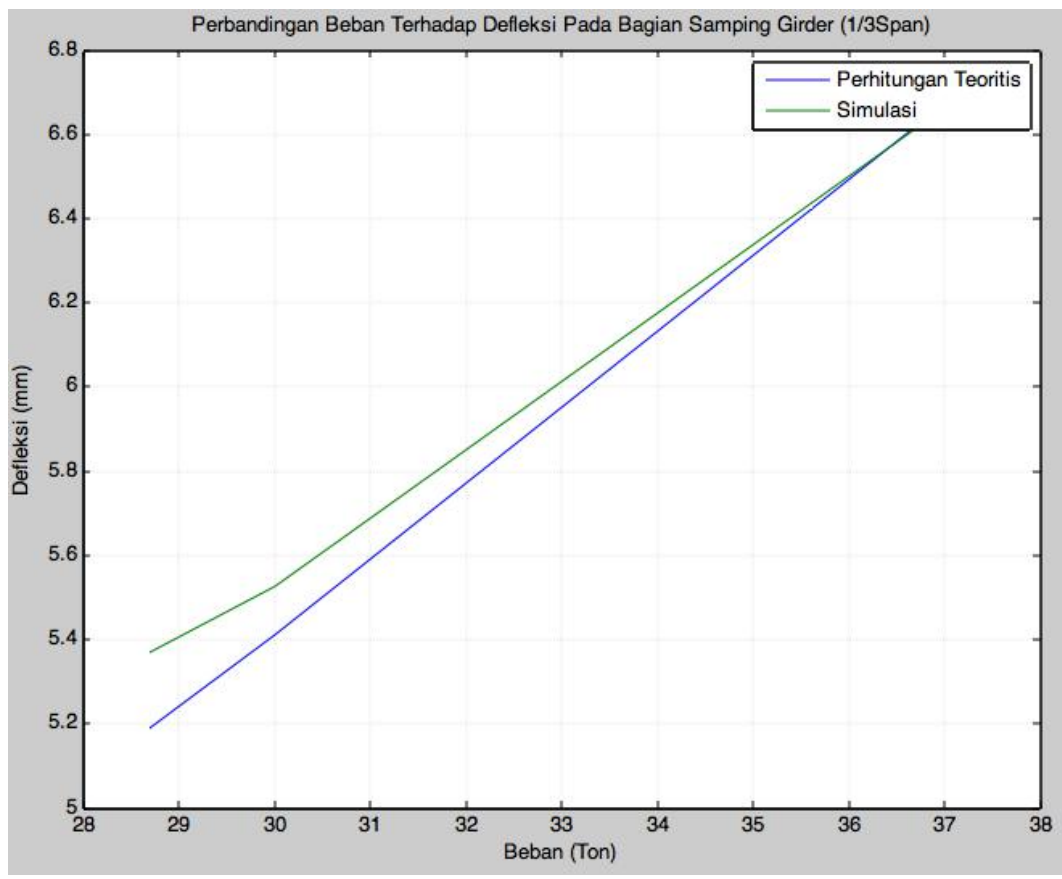

Grafik 5. Grafik perbandingan defleksi terhadap pembebanan pada bagian samping girder (1/3 span)

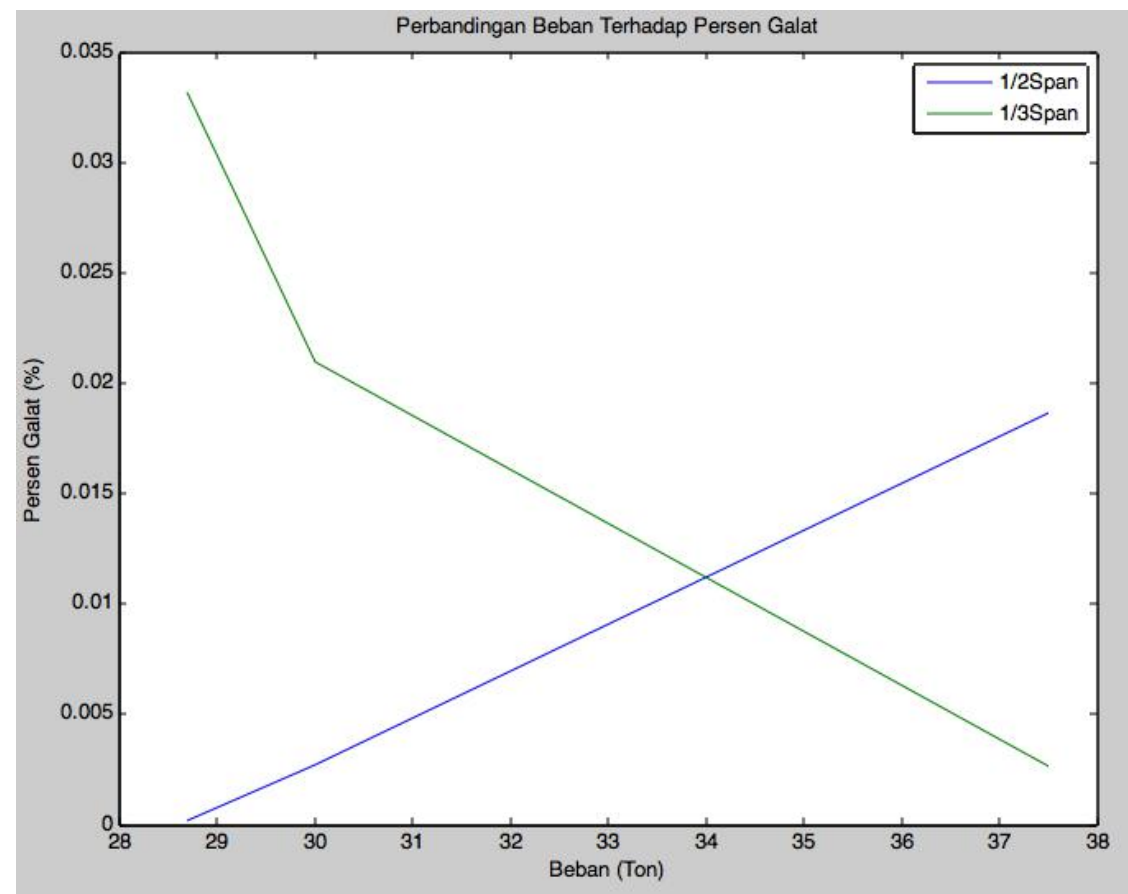

Grafik 6. Grafik perbandingan pembebanan terhadap persen galat hasil perhitungan dan simulasi

Pada tabe 1 dan 2 memperlihatkan hasil defleksi terhadap pembebanan pada bagian tengah girder ( $1 / 2$ span) dan samping girder (1/3 span).Berdasarkan hasil perhitungan teoritis pada 
bagian tengah girder ( $1 / 2$ span) dengan beban 28,7 ton, 30 ton dan 37,5 ton didapatkan besar nilai defleksi (teori) masing masing yaitu $6,060 \mathrm{~mm}, 6,335 \mathrm{~mm}$ dan 7,918 $\mathrm{mm}$ dan besar nilai defleksi (simulasi) masing masing yaitu 6,059 mm, 6,318 $\mathrm{mm}$ dan 7,773 $\mathrm{mm}$. Dan pada bagian samping girder ( $1 / 3$ span) dengan beban 28,7 ton, 30 ton dan 37,5 ton didapatkan besar nilai defleksi (teori) masing masing yaitu $5,191 \mathrm{~mm}, 5,410 \mathrm{~mm}$ dan $6,763 \mathrm{~mm}$ dan besar nilai defleksi (simulasi) masing masing yaitu 5,369 mm, 5,526 mm dan 6,745 mm. semakin besar beban yang dialami batang maka defleksi yang terjadipun semakin besar.

Hasil pembebanan ini memiliki persentase selisih antaran nilai defleksi hasil perhitungan dengan hasil simulasi yang sangat kecil mendekati angka nol, maka dapat diartikan tidak ada galat antara pehitungan dengan simulasi. Untuk pembebanan bagian tengah girder ( $1 / 2 \mathrm{span})$ didapatkan nilai persen galat pada beban 28,7 ton, 30 ton dan 37,5 ton masing masing yaitu $0,00016,0,00269$ dan 0,01865 . Dan pada bagian samping girder ( $1 / 3$ span) didapatkan nilai persen galat pada beban 28,7 ton, 30 ton dan 37,5 ton masing masing yaitu $0,03315,0,02099$ dan 0,00266 .

\section{KESIMPULAN}

Dari hasil penelitian ini disimpulkan bahwa nilai defleksi hasil perhiungan teoritis dan simulasi pada pembebanan di bagian tengah girder ( $1 / 2$ span) dan dibagian samping girder ( $1 / 3$ span) yang lebih kecil daripada nilai defleksi yang diizinkan, ini mengindikasikan bahwa girder overhead crane SWL 30 Ton masih aman untuk melakukan proses pengangkatan baik pada beban dengan berat dibawah 100 SWL, 100 SWL maupun 125 SWL, dan kerusakan komponen girder dapat dihindari.

\section{REFERENSI}

[1] API RP 2D, 2003. Operation and Maintenance of Offshore $5^{\text {th }}$ Edition, American Petroleum Institute

[2] ASME B30.2-2005, 2010. Overhead Crane and Gantry Crane. New York: The American Sosiety of Mechanical Engineers .

[3] C. Alkin, C. E. Imrak, H. Kocabas. Solid Modeling and Finite Element Analysis of an Overhead Crane Bridge. Journal Czech Technical University in Prague.

[4] Erik Oberg, Franklin D Jones, Holbrook L. Horton, and Henry H ryffel. 2000. Machinery's Handbook. New York : Industrial Press Inc

[5] Herbert Morris. 1982. Operation, Manual \& Maintenance Book. Loughborough, UK.

[6] Pinem, Daud. 2010. Mekanika Kekuatan Lanjut. Rekayasa Sains, Bandung. 